\title{
The Role of Dexmedetomidine for the Prevention of Acute Kidney Injury in Critical Care
}

\author{
Authors: \\ Gion Ruegg, ${ }^{1}$ Nora Luethi, ${ }^{2,3}$ * Luca Cioccari ${ }^{1,3}$ \\ 1. Department of Intensive Care Medicine, Inselspital, Bern University Hospital, \\ University of Bern, Bern, Switzerland \\ 2. Department of Emergency Medicine, Inselspital, Bern University Hospital, \\ University of Bern, Bern, Switzerland \\ 3. Australian and New Zealand Intensive Care Research Centre, School of Public \\ Health and Preventive Medicine, Monash University, Prahran, Australia \\ *Correspondence to luca.cioccari@insel.ch
}

Disclosure: $\quad$ The authors have declared no conflicts of interest.

Received: $\quad 12.04 .21$

Accepted: $\quad 03.06 .21$

Keywords: $\quad$ Acute kidney injury (AKI), critical illness, dexmedetomidine (DEX).

Citation: $\quad$ EMJ Nephrol. 2021;9[1]:97-106.

\section{Abstract}

Acute kidney injury ( $\mathrm{AKI}$ ) occurs in up to $50 \%$ of patients admitted to the intensive care unit and is associated with increased mortality. Currently, there is no effective pharmacotherapy for prevention or treatment of AKI. In animal models of sepsis and ischaemia-reperfusion, a2-agonists like dexmedetomidine (DEX) exhibit anti-inflammatory properties and experimental data indicate a potential protective effect of DEX on renal function. However, clinical trials have yielded inconsistent results in critically ill patients. This review discusses the pathophysiological mechanisms involved in $\mathrm{AKI}$, the renal effects of DEX in various intensive care unit-related conditions, and summarises the available literature addressing the use of DEX for the prevention of AKI.

\section{INTRODUCTION}

Acute kidney injury (AKI) is defined by a rapid rise in serum creatinine, a drop in urine output, or both, and occurs in up to $15 \%$ of patients who are hospitalised and up to 50\% of patients admitted to the intensive care unit (ICU). ${ }^{1}$ Major surgery, cardiac surgery, sepsis, cardiorenal, and hepatorenal syndrome are among the most frequent risk factors in critically ill patients. AKI is often part of a syndrome rather than a single pathophysiological entity, and the pathophysiology varies according to the underlying causes and preexisting conditions. Renal hypoperfusion can occur due to hypovolaemia, systemic vasodilatation, increased vascular resistance, cardiac dysfunction, or increased intraabdominal pressure leading to venous congestion. Renal hypoperfusion activates adaptive mechanisms such as vascular autoregulation and stimulation of the sympathetic nervous system and the renin-angiotensin-aldosterone system to maintain glomerular filtration rate (GFR). With prolonged hypoperfusion or inadequate adaptive mechanisms, GFR initially drops without structural damage to the renal parenchyma. However, ischaemic acute tubular necrosis occurs if renal perfusion remains compromised. Likewise, nephrotoxic drugs and endogenous 
toxins like myoglobin and uric acid can have a direct cytotoxic effect, compromise intrarenal haemodynamics, and cause precipitation of crystals or metabolites. ${ }^{2}$ Nearly two-thirds of $\mathrm{AKI}$ cases resolve within a week and in such patients, 12-month survival is over $90 \%$. However, if AKI does not resolve, hospital mortality is significantly increased (47\%) and 12 -month survival is only $77 \%{ }^{3}$ Currently, there is no effective pharmacotherapy for prevention or treatment of AKI. Prevention bundles emphasise risk stratification and avoidance of hypotension, hypoperfusion, and refrainment from nephrotoxic substances. ${ }^{4}$

Dexmedetomidine (DEX) is a centrally acting, highly-selective a2-adrenergic agonist and has become an increasingly popular sedative agent in critical care due to its sedative, anxiolytic, sympatholytic, and analgesic-sparing effects, with minimal depression of the respiratory drive. ${ }^{5}$ Side effects comprise hypertension, hypotension, bradycardia resulting from vasoconstriction, sympatholytic effects, and baroreflex-induced parasympathetic activation. ${ }^{6,7}$

DEX is rapidly distributed and is mainly hepatically metabolised into inactive metabolites by glucuronidation and hydroxylation. Compared with classic sedatives like propofol and benzodiazepines, DEX provides lighter levels of sedation and supplemental analgesic effects. $^{8}$ Patients remain easily rousable with minimal influence on respiratory drive. Moreover, DEX attenuates stress responses, creating a more stable haemodynamic profile during stressful events such as surgery or anaesthetic induction. ${ }^{9-12}$ Finally, DEX improves sleep efficiency and quality. ${ }^{13-14}$

The main advantage of DEX in patients in the ICU is reduction in the incidence of delirium ${ }^{15}$ and duration of mechanical ventilation. $^{16}$ The use of DEX has been recommended over benzodiazepines in patients who are mechanically ventilated as it may be associated with improved outcomes., ${ }^{8,17-19}$ Clinical trials have also demonstrated that DEX-based sedation provides some advantages over usual care, typically with propofol, lorazepam, or midazolam. These advantages include a reduction in the duration of sedation and ICU stay and a possible effect on reducing the duration of delirium. $8,20-22$ The Maximizing Efficacy of Targeted Sedation and Reducing Neurological Dysfunction (MENDS) trial compared DEX with lorazepam. ${ }^{21}$ Sedation with DEX resulted in more time at the targeted level of sedation and more days alive without delirium or coma (median days: 7.0 versus 3.0; $\mathrm{p}=0.01$ ) and a lower prevalence of coma ( $63 \%$ versus $92 \%$; $p<0.001)$. The Safety and Efficacy of Dexmedetomidine Compared with Midazolam (SEDCOM) trial compared DEX to midazolam. ${ }^{22}$ The prevalence of delirium was $54 \%$ in the DEX group versus $76.6 \%$ in patients treated with midazolam, for a difference of $22.6 \%$ (95\% confidence interval: 14-33\%; $\mathrm{p}<0.001)$. Median time to extubation was 1.9 days shorter in the DEX group (3.7 days versus 5.6 days; $\mathrm{p}=0.01$ ). The multicentre, double-blind, placebocontrolled Dexmedetomidine versus Midazolam or Propofol for Sedation During Prolonged Mechanical Ventilation (MIDEX and PRODEX trials), ${ }^{8}$ compared DEX with midazolam and propofol and demonstrated the safety and non-inferiority of DEX as a first-line sedative in patients who were critically ill and on ventilation. Median duration of ventilation was shorter with DEX (123 hours; interquartile range [IQR]: 67-337]) versus midazolam (164 hours; IQR: 92-380; $p=0.03$ ) but not with DEX (97 hours; IQR: 45-257) versus propofol (118 hours; IQR: 48-327; $p=0.24){ }^{8}$ Finally, the pivotal Sedation Practice in Intensive Care Evaluation (SPICE III) trial ${ }^{23}$ randomised 4,000 patients to receive either DEX as the sole or primary sedative or to receive usual care (propofol, midazolam, or other sedatives). Sedation with DEX did not affect overall mortality or mortality in key clinical predefined subgroups. However, it showed statistically significant heterogeneity of treatment effect according to age: DEX-based sedation appeared to increase 90-day mortality in patients below the median age of 63.7 years (relative risk increase of $23.7 \%$ ) and to decrease mortality in patients older than the median trial age (relative risk reduction of 11\%). ${ }^{24}$

a2-agonists like DEX exhibit anti-inflammatory properties and have been ascribed respiratory, cardiac, neurologic, and renal protective effects. ${ }^{25}$ Moreover, DEX inhibits the antidiuretic action of vasopressin, ${ }^{26}$ enhances osmolal clearance, and preserves cortical blood flow by decreasing renal cortical release of noradrenaline (Figure 1). ${ }^{27}$ However, the relevance and 
effect of these effects on clinical outcomes remains uncertain. In this narrative review the authors address the putative reno-protective effects of DEX and summarise the results from clinical and animal studies addressing the use of DEX for the prevention of AKI.

\section{THE ANTI-INFLAMMATORY EFFECTS OF DEXMEDETOMIDINE}

DEX inhibits toll-like receptor-4/NFkB pathway activation and therefore decreases the production of proinflammatory cytokines such as TNF-a and IL-6. ${ }^{28-30}$ These actions are mainly mediated by a2-adrenergic receptor subtypes ${ }^{29,31}$ although other adrenergic-receptorindependent mechanisms, ${ }^{28}$ vagomimetic, and humoral pathways contribute to the antiinflammatory effect. ${ }^{32-34}$ DEX also reduces oxidative stress by attenuating the formation of reactive oxygen species, increasing glutathione levels, inhibiting oxygen consumption, and improving mitochondrial dysfunction. ${ }^{35,36}$ Finally, DEX has been reported to promote resolution of inflammation through activation of so-called specialised pro-resolving lipid mediators. ${ }^{37}$ Among these, lipoxin A4 is one of the most important, and its biosynthesis depends on 5-lipoxygenase and adrenergic receptor activity. Lipoxygenase-5 and lipoxin A4 expression are increased in DEXtreated animals with sepsis, providing evidence that DEX not only inhibits the generation of excessive inflammation but also enhances its resolution. ${ }^{38}$

\section{DEXMEDETOMIDINE FOR THE PREVENTION OF ACUTE KIDNEY INJURY IN CARDIAC SURGERY}

AKI affects up to $30 \%$ of patients undergoing cardiopulmonary bypass (CPB) surgery and is the second most common cause of $A K I$ in the ICU. ${ }^{39}$ Patients undergoing cardiac surgery are particularly at risk, as factors like non-pulsatile perfusion during CPB, hypothermia, coagulopathy, haemolysis, activation of cytokines, complement pathways and the renin-angiotensin-aldosterone system, and pituitary secretion of argininevasopressin in response to low-flow states result in microcirculatory and renal vasoconstriction.

Anti-inflammatory effects:

$\downarrow$ Inflammatory cytokines (TNF- $\alpha$, IL-6)

$\downarrow$ Oxidative stress, $\downarrow$ ROS

$\uparrow$ Glutathione levels

$\uparrow$ Mitochondrial function

$\uparrow$ Resolution of inflammation (SPM)
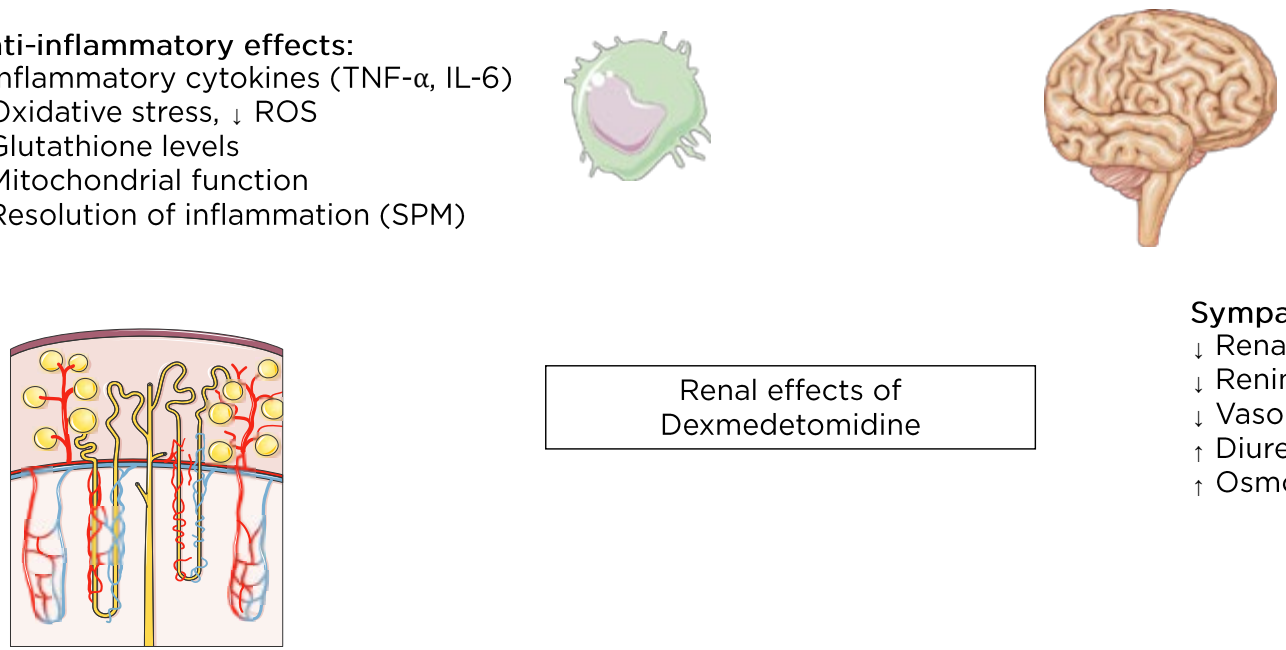

Sympatholytic effects:

$\downarrow$ Renal sympathetic activity

Renin release

$\downarrow$ Vasopressin release

$\uparrow$ Diuresis, natriuresis

$\uparrow$ Osmolal clearance

Preserves cortical blood flow:

$\downarrow$ Renal cortical release of noradrenaline

$\downarrow$ Noradrenaline requirements

$\uparrow$ Vascular sensitivity to vasopressors
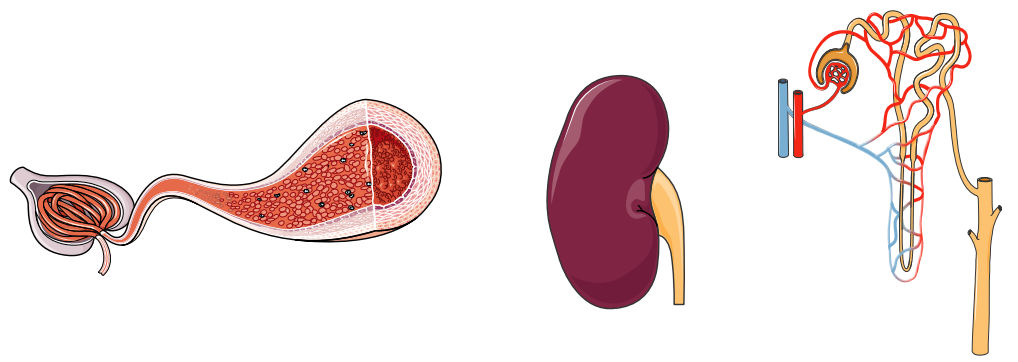

Figure 1: Overview of the renal effects of dexmedetomidine.

ROS: reactive oxygen species; SPM: specialised pro-resolving mediators. 
Moreover, release of aortic cross-clamping leads to reperfusion injury and further cellular damage.

Clinical and animal studies point towards a protective effect of DEX against $A K I$ in this setting. In rodent models of ischaemia-reperfusion (I-R), intraperitoneal administration of DEX at doses between 10 and $100 \mu \mathrm{g} / \mathrm{kg}$ reduced inflammation and histomorphological signs of renal injury. ${ }^{31,34,40-45}$ However, these protective effects could not be replicated in studies where DEX was given intravenously (dose range: 1-3 $\mu \mathrm{g} / \mathrm{kg} /$ hour). ${ }^{46,47}$ Nevertheless, in patients undergoing cardiac surgery, DEX appears to decrease the incidence of postoperative AKI. Several clinical trials have assessed the effect of DEX in this patient population, and DEX improves tradition$\mathrm{al}^{48}$ and modern renal biomarkers ${ }^{49,50}$ and renal function in most studies. ${ }^{51,52}$ A meta-analysis and trial sequential analysis of nine randomised controlled trials (RCTs) with a total of 1,308 patients found robust evidence that DEX significantly reduced the incidence of AKI after cardiac surgery (risk ratio: 0.60; 95\% confidence interval: $0.41-0.87 ; p=0.008) .{ }^{53}$ The protective effect on AKI was most evident when DEX was administered pre- or intraoperatively and in patients aged over 60 years. DEX also reduced time to extubation and incidence of delirium. There were no significant differences in other postoperative complications, urine output, length of ICU stay, and mortality. Compared to the earlier meta-analyses, ${ }^{54,55}$ summarised in Table 1, ${ }^{53-56}$ the study by Peng et $a .^{53}$ used a more robust and transparent methodology. However, as the studies included in this systematic review covered nearly a decade, different definitions of $A K I$ were used. Therefore, the effect of DEX on incidence of $\mathrm{AKI}$ after cardiac surgery under a common definition remains unclear.

Several factors need to be considered when interpreting the results of trials and meta-analyses addressing the role of DEX for prevention of AKI. Many patients undergoing cardiac surgery have pre-existent renal dysfunction or comorbidities that make the kidneys more vulnerable to injury. As outlined above, the CPB procedure itself, aortic cross-clamping time, transfusion of blood products, high doses of vasopressors, and inotropes all contribute to the development of postoperative AKI. Therefore, any baseline variability regarding these factors between trial participants may significantly undermine the value of a meta-analysis. The potential protective role of DEX in AKI can only be appreciated when timing and dose of the intervention, type and duration of surgery, patient characteristics, and perioperative therapeutic strategies are considered.

\section{DEXMEDETOMIDINE FOR THE PREVENTION OF ACUTE KIDNEY INJURY IN NON-CARDIAC SURGERY}

Postoperative AKI affects approximately onefifth of patients after major surgery. ${ }^{57}$ Major surgery is among the most common risk factors for $\mathrm{AKI}$, as it frequently implicates significant shifts in intravascular volume, transient hypotension, and the exposure to nephrotoxic substances including contrast media, antibiotics, and non-steroidal antiinflammatory drugs. Increased levels of circulating cytokines and reactive oxygen species due to endotoxins from compromised visceral perfusion and I-R injury contribute to renal injury. ${ }^{58}$ Furthermore, advanced age and preexisting comorbidities including diabetes, chronic renal failure, and heart failure increase the risk for developing AKI, ${ }^{1}$ and complex surgical interventions are performed in older and sicker individuals, thus increasing numbers of patients at risk. ${ }^{59}$

Experimental and clinical data on the effect of DEX on postoperative AKI in non-cardiac surgery are rare (an overview of relevant studies in humans is given in Table 2). ${ }^{20,60-63}$ In a rat model of orthotopic liver transplantation, intraperitoneal DEX $(10 \mu \mathrm{g} / \mathrm{kg})$ decreased blood urea nitrogen (BUN) and serum creatinine levels and reduced histopathological kidney injury. ${ }^{29}$ However, in a single-centre retrospective cohort study of 1,207 patients, the use of intraoperative DEX was not associated with a decline in AKI after lung cancer surgery. A pilot RCT of 89 patients undergoing laparoscopic radical prostatectomy found that, compared to normal saline, an intravenous bolus of $1 \mu \mathrm{g} / \mathrm{kg}$ DEX at the start of surgery lowered the incidence of $\mathrm{AKI}$ and serum level of renal biomarkers like BUN, creatinine, and cystatin C. ${ }^{60}$ 
Table 1: Summary of published meta-analyses on the effect of dexmedetomidine on acute kidney injury.

\begin{tabular}{|c|c|c|c|c|c|}
\hline Study & $\begin{array}{l}\text { Patient } \\
\text { population }\end{array}$ & $N$ & Studies included & Primary outcome & Main results \\
\hline Peng et al. ${ }^{53} 2020$ & $\begin{array}{l}\text { Adult cardiac } \\
\text { surgery }\end{array}$ & 1,308 & 9 RCTs & Incidence of AKI & $\begin{array}{l}\text { DEX reduced } \\
\text { incidence of } \mathrm{AKI} \\
\text { (RR: } 0.60 ; 95 \% \\
\mathrm{Cl}: 0.41-0.87 ; \\
\mathrm{p}=0.008)\end{array}$ \\
\hline Liu et al. ${ }^{54} 2018$ & $\begin{array}{l}\text { Adult cardiac } \\
\text { surgery }\end{array}$ & 1,575 & $10 \mathrm{RCTs}$ & $\begin{array}{l}\text { Incidence of AKI } \\
\text { within } 7 \text { days }\end{array}$ & $\begin{array}{l}\text { DEX reduced } \\
\text { incidence of AKI } \\
\text { (OR: } 0.65 ; 95 \% \\
\mathrm{Cl}: 0.45-0.92 ; \\
\mathrm{p}=0.02 \text { ) }\end{array}$ \\
\hline Shi and Tie 2017 & $\begin{array}{l}\text { Adult cardiac } \\
\text { surgery }\end{array}$ & 19,266 & $\begin{array}{l}3 \text { RCTs } \\
4 \text { observational }\end{array}$ & Incidence of AKI & $\begin{array}{l}\text { DEX reduced } \\
\text { incidence of } \mathrm{AKI} \\
\text { in the RCTs } \\
\text { (RR: } 0.44 ; 95 \% \\
\mathrm{Cl}: 0.26-0.76 ; \\
\mathrm{p}=0.003 \text { ) and } \\
\text { cohort studies } \\
\text { (RR: } 0.74 ; 95 \% \\
\mathrm{Cl}: 0.63-0.86 ; \\
\mathrm{p}=0.0001)\end{array}$ \\
\hline Li et al. ${ }^{56} 2018$ & $\begin{array}{l}\text { Paediatric cardiac } \\
\text { surgery }\end{array}$ & 1,851 & $\begin{array}{l}5 \text { RCTs } \\
4 \text { observational }\end{array}$ & $\begin{array}{l}\text { Postoperative } \\
\text { junctional ectopic } \\
\text { tachycardia and } \\
\text { AKI }\end{array}$ & $\begin{array}{l}\text { No difference in } \\
\text { AKI } \\
\text { (OR: 0.44; 95\% Cl: } \\
\text { O.19-1.04; } p=0.06 \text { ) } \\
\text { AKI reported in } \\
73 / 233 \text { patients } \\
(31.3 \% \text { ) among } \\
\text { one RCT and one } \\
\text { observational } \\
\text { study }\end{array}$ \\
\hline
\end{tabular}

AKI: acute kidney injury; Cl: confidence interval; DEX: dexmedetomidine; N: number of patients; OR: odds ratio; RCT: randomised controlled trial; RR: risk ratio.

Table 2: Characteristics of relevant studies on the effect of dexmedetomidine on acute kidney injury in non-cardiac surgery patients.

\begin{tabular}{|c|c|c|c|c|c|c|c|c|c|}
\hline Reference & Study design & $\begin{array}{l}\text { Patient } \\
\text { population }\end{array}$ & $N$ & Blinding & Dose & Timing & $\begin{array}{l}\text { Control } \\
\text { group }\end{array}$ & $\begin{array}{l}\text { Primary } \\
\text { outcome }\end{array}$ & Main results \\
\hline $\begin{array}{l}\text { Kawazoe } \\
\text { et al. }{ }^{20} \\
2017\end{array}$ & $\mathrm{RCT}$ & $\begin{array}{l}\text { Sepsis and } \\
\text { mechanical } \\
\text { ventilation for } \\
>24 \text { hours }\end{array}$ & 201 & No & $\begin{array}{l}0.1-0.7 \mu \mathrm{g} / \\
\mathrm{kg} / \mathrm{hour} \mathrm{IV}\end{array}$ & $\begin{array}{l}\text { After } 24 \\
\text { hours }\end{array}$ & $\begin{array}{l}\text { Propofol/ } \\
\text { midazolam }\end{array}$ & $\begin{array}{l}\text { Mortality } \\
\text { and } \\
\text { ventilator- } \\
\text { free days } \\
\text { at Day } 28\end{array}$ & $\begin{array}{l}\text { No } \\
\text { difference } \\
\text { in } \\
\text { (secondary) } \\
\text { renal } \\
\text { outcomes } \\
\text { (urinary } \\
\text { output, } \\
\text { creatinine, } \\
\text { eGFR, BUN) }\end{array}$ \\
\hline
\end{tabular}


Table 2 continued.

\begin{tabular}{|c|c|c|c|c|c|c|c|c|c|}
\hline Reference & Study design & $\begin{array}{l}\text { Patient } \\
\text { population }\end{array}$ & $N$ & Blinding & Dose & Timing & $\begin{array}{l}\text { Control } \\
\text { group }\end{array}$ & $\begin{array}{l}\text { Primary } \\
\text { outcome }\end{array}$ & Main results \\
\hline $\begin{array}{l}\text { Liu et al. }{ }^{78} \\
2015\end{array}$ & RCT & $\begin{array}{l}\text { Septic } \\
\text { shock and } \\
\text { mechanical } \\
\text { ventilation }\end{array}$ & 200 & NR & $\begin{array}{l}1 \mu \mathrm{g} / \mathrm{kg} \\
\text { bolus, then } \\
0.2-0.3 \\
\mu \mathrm{g} / \mathrm{kg} / \\
\text { hour IV }\end{array}$ & $\begin{array}{l}\text { From ICU } \\
\text { admission } \\
\text { until Day } \\
5\end{array}$ & Propofol & NR & $\begin{array}{l}\text { Incidence } \\
\text { of AKI } \\
38.1 \% \text { in the } \\
\text { DEX group } \\
\text { versus } \\
59.6 \% \text { in } \\
\text { controls } \\
\text { (OR: O.76; } \\
95 \% \mathrm{Cl} \text { : } \\
0.13-0.77 ; \\
\mathrm{p}=0.046 \text { ) }\end{array}$ \\
\hline $\begin{array}{l}\text { Wu et al. }{ }^{60} \\
2019\end{array}$ & $\mathrm{RCT}$ & $\begin{array}{l}\text { Laparoscopic } \\
\text { radical } \\
\text { prostatectomy }\end{array}$ & 89 & $\begin{array}{l}\text { Double- } \\
\text { blind }\end{array}$ & $\begin{array}{l}1 \mu \mathrm{g} / \mathrm{kg} \\
\text { bolus, then } \\
0.5 \mu \mathrm{g} / \mathrm{kg} / \\
\text { hour IV }\end{array}$ & $\begin{array}{l}\text { During } \\
\text { surgery }\end{array}$ & $0.9 \% \mathrm{NaCl}$ & $\begin{array}{l}\text { Incidence } \\
\text { of } \mathrm{AKI}\end{array}$ & $\begin{array}{l}\text { AKI in the } \\
\text { DEX group } \\
2 / 44(4.5 \%) \\
\text { versus } 6 / 45 \\
(13.3 \%) \text { in } \\
\text { controls } \\
(p=0.281) .\end{array}$ \\
\hline $\begin{array}{l}\text { Zhang et } \\
\text { al. }^{61} 2019\end{array}$ & RCT & $\begin{array}{l}\text { Pre-eclampsia } \\
\text { undergoing } \\
\text { caesarean } \\
\text { section }\end{array}$ & 134 & $\begin{array}{l}\text { Double- } \\
\text { blind }\end{array}$ & $\begin{array}{l}\text { Intrathecal: } \\
0.6-0.4 \\
\mu \mathrm{g} / \mathrm{kg} / \mathrm{min} \\
\mathrm{IV}: 0.4 \mu \mathrm{\mu g} / \\
\mathrm{kg} / \mathrm{min}\end{array}$ & $\begin{array}{l}\text { During/ } \\
\text { before } \\
\text { surgery }\end{array}$ & $0.9 \% \mathrm{NaCl}$ & NR & $\begin{array}{l}\text { B2-MG, } \\
\text { KIM-1, } \\
\text { and urine } \\
\text { protein } \\
\text { lower in } \\
\text { the DEX } \\
\text { group. No } \\
\text { significant } \\
\text { difference } \\
\text { in BUN, } \\
\text { creatinine, } \\
\text { or urine } \\
\text { output. }\end{array}$ \\
\hline
\end{tabular}

AKI: acute kidney injury; BUN: blood urea nitrogen; B2-MG: B2-microglobulin; Cl: confidence interval; DEX: dexmedetomidine; eGFR: estimated glomerular filtration rate; ICU: intensive care unit; IV: intravenous; KIM-1: kidney injury molecule-1; N: number of patients; NA: not applicable; NaCl: sodium chloride; NR: not reported; OR: odds ratio; RCT: randomised controlled trial.

However, this was a small, underpowered pilot study and the overall incidence of AKI was low $(4.5 \%$ in the DEX group and $13.3 \%$ in the control group), thus increasing the risk of a Type-I error. In a recent double-blind placebo-controlled
RCT in 134 women undergoing caesarean section for pre-eclampsia, intravenous DEX $(0.4 \mu \mathrm{g} / \mathrm{kg} /$ min for 10 minutes before surgery) resulted in lower B2-microglobulin, kidney injury molecule-1, and urine protein, but not in significant 
differences in BUN, serum creatinine, or urine output. ${ }^{61}$

\section{DEXMEDETOMIDINE FOR THE PREVENTION OF ACUTE KIDNEY INJURY IN SEPSIS}

AKI occurs in up to $50 \%$ of patients with sepsis, onethird of whom do not survive. ${ }^{64}$ Although sepsis is the most common cause of severe AKI in patients in the ICU, the exact mechanisms are still under investigation. ${ }^{65}$ An increased level of inflammatory cytokines and leukocyte activity can lead to the capillary microthrombi resulting in microvascular dysfunction. Redistribution of intrarenal blood flow due to abnormal vascular tone and shunting, renal inflammation, and oedema can decrease capillary perfusion and oxygen delivery. Sepsis-induced hypotension in addition to the microcirculatory dysfunction can further impair perfusion and oxygen delivery to the kidneys due to renal medullary tissue hypoperfusion and hypoxia. ${ }^{66,67}$ Early onset of renal medullary hypoxia and tissue ischaemia occurs hours before the development of $\mathrm{AKI}$, despite elevated or unchanged renal blood flow, renal oxygen delivery, and renal cortical perfusion and oxygenation. . $^{6-70}$

The reno-protective effects of DEX in animal models have been related to its anti-inflammatory properties, which can attenuate sepsis-induced microcirculatory dysfunction. ${ }^{71}$ Both clonidine and DEX reduce the levels of pro-inflammatory cytokines (TNF-a and IL-6), while preserving the levels of an anti-inflammatory cytokine (IL-10) in septic sheep with $\mathrm{AKI}^{72,73}$ In rodent models, DEX protects against $\mathrm{AKI}$, although treatment was given either intraperitoneally ${ }^{35,72-74}$ or prior to sepsis. ${ }^{38,77-79}$ A single-centre clinical trial in 200 patients with sepsis found reductions in plasma inflammatory cytokines (TNF-a and IL-1), serum creatinine, and urinary injury biomarkers in patients receiving DEX $(1 \mu \mathrm{g} / \mathrm{kg}$ bolus at ICU admission, and then $0.2-0.3 \mu \mathrm{g} / \mathrm{kg} /$ hour for 5 days) compared with propofol. ${ }^{62}$ However, the findings of this trial must be interpreted with caution as the primary outcome was not clearly defined, no sample size calculation was provided, the study protocol was not published a priori, and blinding and randomisation were not described.
In agreement with experimental findings, renal medullary tissue hypoxia has recently been indirectly demonstrated in humans with sepsis by measurable declines in bladder urinary oxygenation. ${ }^{81}$ Administration of noradrenaline can aggravate renal medullary ischaemia and hypoxia. ${ }^{68,69,82}$ In patients with sepsis, coadministration of DEX reduces noradrenaline requirements to attain the target blood pressure, ${ }^{83}$ an effect associated with preservation of renal medullary perfusion, renal medullary oxygenation, and kidney function. ${ }^{73}$ In the Dexmedetomidine for Sepsis in Intensive Care Unit (DESIRE) trial ( $N=201$ patients) DEX did not significantly affect renal outcomes or 28-day mortality. ${ }^{20}$ However, a recent sub-group analysis of 104 patients with severe sepsis (Acute Physiology and Chronic Evaluation II scores of $\geq 23$ ) found lower serum creatinine levels, improvements in renal Sequential Organ Failure Assessment (SOFA) sub-scores, and a decrease in 28-day mortality (22\% versus $42 \%$ ) in the DEX group. ${ }^{84}$

Despite the current lack of convincing clinical evidence to prove the renal benefits of DEX in patients with sepsis, data from animal studies support strategies that protect the kidneys from I-R injury. ${ }^{85}$ Although it is conceivable that DEX provides a protective effect in the evolution of $\mathrm{AKI}$, its effect on longterm outcomes remains unknown. In a rat model, Liu et al. ${ }^{42}$ demonstrated that DEX improved histological signs of renal injury up to 8 weeks after renal clamping. However, most randomised clinical trials found either only a transient effect on renal parameters or provided only shortterm follow up in the range of a couple of days. The DESIRE trial$^{20}$ showed no difference in $A K I$, a secondary outcome, after 28 days and the above-mentioned sub-group analysis by Nakashima et al. ${ }^{84}$ found significantly lower serum creatinine but no difference in urinary output in the first 14 days.

\section{CONCLUSIONS AND FUTURE DIRECTIONS}

Numerous animal studies suggest a renoprotective effect of DEX after a controlled insult such as I-R injury or experimental sepsis. These effects are more reproducible with 
intraperitoneal injection of DEX, compared to the more clinically relevant intravenous route. In clinical practice, three meta-analyses confirm a beneficial effect of DEX on renal function in patients after cardiac surgery. However, the evidence for similar benefits in patients with sepsis or in non-cardiac surgery is less convincing. An important difference between these trials is the timing of DEX administration relative to the noxious insult. While in cardiac surgery the onset of CPB is predictable, it is impossible to predict the exact time of onset of sepsis, massive blood loss, or hypotension. Importantly, due to its sympatholytic properties, DEX may aggravate haemodynamic instability, raising concern for additional renal hypoperfusion with its use. However, in their systematic review, Peng et al. ${ }^{53}$ did not find any differences in hypotension or bradycardia or the need for vasopressors with DEX use, and, in patients with sepsis, DEX may actually decrease vasopressor requirements. ${ }^{83}$ Moreover, a high inter-individual variability in DEX pharmacokinetics has been described, especially in patients in the ICU and body size, liver function, plasma albumin, and cardiac output all have a significant impact on DEX pharmacokinetics. ${ }^{5}$ As outlined above, any baseline variability regarding these factors among trial participants must be considered when interpreting the results of clinical trials.

The assessment of the incidence of $A K I$ in different patient populations has been complicated by the various definitions for AKI used over time. ${ }^{85}$ The challenges in applying diagnostic criteria in the critically ill patient are considerable. If the true baseline creatinine level is not available and a 'baseline' creatinine level is obtained only after a significant amount of intravenous fluid has been administered, AKI diagnosis may be falsely common because the 'baseline' creatinine value may be falsely low due to haemodilution is these settings. ${ }^{86}$ Moreover, ongoing fluid administration can decrease serum creatinine concentration and thereby conceal loss of GFR in such patients. Finally, the widespread use of diuretics and intravenous fluids in the perioperative period may render urine output an unreliable indicator of true renal function. Future trials are needed to determine the dose and timing of DEX in improving outcomes in different patient populations, especially in patients with decreased baseline kidney function.

\section{References}

1. Ronco $\mathrm{C}$ et al. Acute kidney injury. Lancet 2019;394(10212):1949-64.

2. Makris K, Spanou L. Acute kidney injury: definition, pathophysiology and clinical Phenotypes. Clin Biochem Rev. 2016;37(2):85-98.

3. Kellum JA et al. Recovery after acute kidney injury. Am J Respir Crit Care Med. 2017;195(6):784-91.

4. Meersch $M$ et al. Prevention of cardiac surgery-associated AKI by implementing the KDIGO guidelines in high risk patients identified by biomarkers: the PrevAKI randomized controlled trial. Intensive Care Med. 2017;43(11):1551-61.

5. Weerink MAS et al. Clinical pharmacokinetics and pharmacodynamics of dexmedetomidine. Clin Pharmacokinet. 2017;56(8):893-913.

6. Ebert TJ et al. The effects of increasing plasma concentrations of dexmedetomidine in humans. Anesthesiology. 2000;93(2):382-94.

7. MacMillan LB et al. Central hypotensive effects of the alpha2a- adrenergic receptor subtype. Science. 1996;273(5276):801-3.

8. Jakob SM et al. Dexmedetomidine vs midazolam or propofol for sedation during prolonged mechanical ventilation: two randomized controlled trials. JAMA. 2012;307(11):1151-60.

9. Hall JE et al. Sedative, amnestic, and analgesic properties of small-dose dexmedetomidine infusions. Anesth Analg 2000;90(3):699-705.

10. Kunisawa $T$ et al. Dexmedetomidine can stabilize hemodynamics and spare anesthetics before cardiopulmonary bypass. J Anesth 2011;25(6):818-22.

11. Sulaiman $\mathrm{S}$ et al. The effects of dexmedetomidine on attenuation of stress response to endotracheal intubation in patients undergoing elective off-pump coronary artery bypass grafting. Ann Card Anaesth. 2012;15(1):39-43.

12. Yildiz $M$ et al. Effect of dexmedetomidine on haemodynamic responses to laryngoscopy and intubation: perioperative haemodynamics and anaesthetic requirements. Drugs $\mathrm{R} D$. 2006;7(1):43-52.

13. Alexopoulou $\mathrm{C}$ et al. Effects of dexmedetomidine on sleep quality in critically ill patients: a pilot study. Anesthesiology. 2014;121(4):801-7.

14. Wu XH et al. Low-dose dexmedetomidine improves sleep quality pattern in elderly patients after noncardiac surgery in the intensive care unit: a pilot randomized controlled Trial. Anesthesiology. 2016;125(5):979-91.

15. Djaiani G et al. Dexmedetomidine versus propofol sedation reduces delirium after cardiac surgery: a randomized controlled trial. Anesthesiology. 2016;124(2):362-8.

16. Gallego-Ligorit $L$ et al. Use of dexmedetomidine in cardiothoracic and vascular anesthesia. J Cardiothorac Vasc Anesth. 2018;32(3):1426-38.

17. Zamani MM et al. Survival benefits of dexmedetomidine used for sedating septic patients in intensive care setting: a systematic review. J Crit 
Care. 2016;32:93-100.

18. Reade MC et al. Effect of dexmedetomidine added to standard care on ventilator-free time in patients with agitated delirium: a randomized clinical trial. JAMA. 2016;315(14):1460-8.

19. Su $X$ et al. Dexmedetomidine for prevention of delirium in elderly patients after non-cardiac surgery: a randomised, double-blind, placebo-controlled trial. Lancet. 2016;388(10054):1893-902.

20. Kawazoe $Y$ et al. Effect of dexmedetomidine on mortality and ventilator-free days in patients requiring mechanical ventilation with sepsis: a randomized clinical trial. JAMA. 2017;317(13):1321-8.

21. Pandharipande PP et al. Effect of sedation with dexmedetomidine vs lorazepam on acute brain dysfunction in mechanically ventilated patients: the MENDS randomized controlled trial. JAMA. 2007;298(22):2644-53.

22. Riker RR et al. Dexmedetomidine vs midazolam for sedation of critically ill patients: a randomized trial. JAMA. 2009;301(5):489-99.

23. Shehabi $Y$ et al. Early sedation with dexmedetomidine in critically ill patients. N Engl J Med. 2019;380(26):2506-17.

24. Shehabi $Y$ et al. Early sedation with dexmedetomidine in ventilated critically ill patients and heterogeneity of treatment effect in the SPICE III randomised controlled trial. Intensive Care Med. 2021;47(4):455-66.

25. Lankadeva YR et al. Emerging benefits and drawbacks of alpha2 -adrenoceptor agonists in the management of sepsis and critical illness. Br J Pharmacol. 2021;178:140725.

26. Rouch AJ et al. Dexmedetomidine inhibits osmotic water permeability in the rat cortical collecting duct. J Pharmacol Exp Ther. 1997;281(1):62-9.

27. Billings FT et al. alpha2-Adrenergic agonists protect against radiocontrast-induced nephropathy in mice. Am J Physiol Renal Physiol. 2008;295(3):F741-8.

28. Zhang $\mathrm{J}$ et al. The effect of dexmedetomidine on inflammatory response of septic rats. BMC Anesthesiol. 2015;15:68.

29. Yao $\mathrm{H}$ et al. Dexmedetomidine inhibits TLR4/NF-KB activation and reduces acute kidney injury after orthotopic autologous liver transplantation in rats. Sci Rep. 2015;5:16849.

30. Bulow NM et al. Dexmedetomidine decreases the inflammatory response to myocardial surgery under minicardiopulmonary bypass. Braz J Med Biol Res. 2016:49(4):e4646.

31. Gu J et al. Dexmedetomidine provides renoprotection against ischemia-reperfusion injury in mice. Crit Care. 2011;15(3):R153.

32. $\mathrm{Hu} \mathrm{J}$ et al. Dexmedetomidine prevents cognitive decline by enhancing resolution of high mobility group box 1 protein-induced inflammation through a vagomimetic action in mice. Anesthesiology. 2018:128(5):921-31.

33. Chen $Y$ et al. Dexmedetomidine ameliorates acute stress-induced kidney injury by attenuating oxidative stress and apoptosis through inhibition of the ROS/JNK signaling pathway. Oxid Med Cell Longev. 2018;2018:4035310.

34. Si $Y$ et al. Dexmedetomidine protects against renal ischemia and reperfusion injury by inhibiting the JAK/STAT signaling activation. J Transl Med. 2013;11:141.

35. Yao $Y$ et al. Dexmedetomidine alleviates lipopolysaccharide-induced acute kidney injury by inhibiting the NLRP3 inflammasome activation via regulating the TLR4/NOX4/ NF-kB pathway. J Cell Biochem. 2019;120(10):18509-23.

36. Kiyonaga $\mathrm{N}$ et al. Effects of dexmedetomidine on lipopolysaccharide-induced acute kidney injury in rats and mitochondrial function in cell culture. Biomed Pharmacother. 2020;125:109912.

37. Cioccari $L$ et al. Lipid mediators in critically ill patients: a step towards precision medicine. Front Immunol. 2020;11:599853.

38. Qiu R et al. Dexmedetomidine restores septic renal function via promoting inflammation resolution in a rat sepsis model. Life Sci. 2018:204:1-8.

39. Wang Y, Bellomo R. Cardiac surgery-associated acute kidney injury: risk factors, pathophysiology and treatment. Nat Rev Nephrol. 2017;13(11):697-711.

40. Li $Q$ et al. Dexmedetomidine attenuates renal fibrosis via a2adrenergic receptor-dependent inhibition of cellular senescence after renal ischemia/reperfusion. Life Sci. 2018;207:1-8

41. Cakir $M$ et al. The effect of dexmedetomidine against oxidative and tubular damage induced by renal ischemia reperfusion in rats. Ren Fail. 2015;37(4):704-8.

42. Liu $\mathrm{G}$ et al. Dexmedetomidine preconditioning inhibits the long term inflammation induced by renal ischemia/reperfusion injury in rats. Acta Cir Bras. 2016;31:8-14.

43. Gonullu E et al. Comparison of the effects of dexmedetomidine administered at two different times on renal ischemia/reperfusion injury in rats. Braz J Anesthesiol. 2014;64(3):152-8.
44. Karahan MA et al. Curcumin and dexmedetomidine prevents oxidative stress and renal injury in hind limb ischemia/reperfusion injury in a rat model. Ren Fail. 2016;38(5):693-8.

45. Kocoglu $\mathrm{H}$ et al. Effect of dexmedetomidine on ischemiareperfusion injury in rat kidney: a histopathologic study. Ren Fail. 2009:31(1):70-4.

46. Curtis FG et al. Dexmedetomidine and $\mathrm{S}(+)$-ketamine in ischemia and reperfusion injury in the rat kidney. Acta Cir Bras. 2011;26(3):202-6.

47. de Carvalho AL et al.

Dexmedetomidine on renal ischemiareperfusion injury in rats: assessment by means of NGAL and histology. Ren Fail. 2015:37(3):526-30.

48. Balkanay 00 et al. The dose-related effects of dexmedetomidine on renal functions and serum neutrophil gelatinase-associated lipocalin values after coronary artery bypass grafting: a randomized, triple-blind, placebocontrolled study. Interact Cardiovasc Thorac Surg. 2015;20(2):209-14.

49. Ammar AS et al. Cardiac and renal protective effects of dexmedetomidine in cardiac surgeries: a randomized controlled trial. Saudi J Anaesth. 2016;10(4):395401.

50. Zhai $M$ et al. The effect of dexmedetomidine on renal function in patients undergoing cardiac valve replacement under cardiopulmonary bypass: A double-blind randomized controlled trial. J Clin Anesth. 2017;40:33-8

51. Cho JS et al. Perioperative dexmedetomidine reduces the incidence and severity of acute kidney injury following valvular heart surgery. Kidney Int. 2016;89(3):693700 .

52. Ji F et al. Post-bypass dexmedetomidine use and postoperative acute kidney injury in patients undergoing cardiac surgery with cardiopulmonary bypass. PLoS One. 2013;8(10):e77446

53. Peng $\mathrm{K}$ et al. Effect of dexmedetomidine on cardiac surgery-associated acute kidney injury: a meta-analysis with trial sequential analysis of randomized controlled trials. J Cardiothorac Vasc Anesth. 2020;34(3):603-13.

54. Liu $Y$ et al. Dexmedetomidine prevents acute kidney injury after adult cardiac surgery: a meta-analysis of randomized controlled trials. BMC Anesthesiol. 2018;18(1):7.

55. Shi R, Tie HT. Dexmedetomidine as a promising prevention strategy for cardiac surgery-associated acute kidney injury: a meta-analysis. Crit Care. 2017;21(1):198.

56. Li $X$ et al. Efficacy of dexmedetomidine in prevention of junctional ectopic tachycardia and 
acute kidney injury after pediatric cardiac surgery: a meta-analysis Congenit Heart Dis. 2018;13(5):799807

57. Uchino $\mathrm{S}$ et al. Acute renal failure in critically ill patients: a multinational multicenter study. JAMA. 2005;294(7):813-8.

58. Vaara ST, Bellomo R. Postoperative renal dysfunction after noncardiac surgery. Curr Opin Crit Care. 2017;23(5):440-6.

59. Etzioni DA et al. The aging population and its impact on the surgery workforce. Ann Surg. 2003;238(2):170-7.

60. Wu S et al. Determining whether dexmedetomidine provides a renoprotective effect in patients receiving laparoscopic radical prostatectomy: a pilot study. Int Urol Nephrol. 2019;51(9):1553-61.

61. Zhang QL et al. Protective effect of dexmedetomidine on kidney injury of parturients with preeclampsia undergoing cesarean section: a randomized controlled study. Biosci Rep. 2019:39(5):BSR20190352.

62. Liu J et al. Dexmedetomidine protects against acute kidney injury in patients with septic shock. Ann Palliat Med. 2020;9(2):224-30

63. Moon $\mathrm{T}$ et al. The use of intraoperative dexmedetomidine is not associated with a reduction in acute kidney injury after lung cancer surgery. J Cardiothorac Vasc Anesth. 2016;30(1):51-5.

64. Bagshaw SM et al. Septic acute kidney injury in critically ill patients: Clinical characteristics and outcomes. Clin J Am Soc Nephrol. 2007;2(3):431-9.

65. Bellomo R et al. Acute kidney injury in sepsis. Intensive Care Med. 2017;43(6):816-28

66. Ma S et al. Sepsis-induced acute kidney injury: a disease of the microcirculation. Microcirculation. 2019;26(2):e12483.

67. Evans R et al. Renal haemodynamics and oxygenation during and after cardiac surgery and cardiopulmonary bypass. Acta Physiol.

2018;222:e12995.

68. Lankadeva $Y$ et al. Urinary oxygenation as a surrogate marker of medullary oxygenation during angiotensin II therapy in septic acute kidney injury. Crit Care Med. 2018;46:e41-8.

69. Lankadeva YR et al. Intrarenal and urinary oxygenation during norepinephrine resuscitation in ovine septic acute kidney injury. Kidney Int 2016;90(1):100-8.

70. Calzavacca P et al. Cortical and medullary tissue perfusion and oxygenation in experimental septic acute kidney injury. Crit Care Med. 2015;43(10):e431-9.

71. Miranda ML et al. Dexmedetomidine attenuates the microcirculatory derangements evoked by experimental sepsis. Anesthesiology. 2015;122(3):619-30.

72. Calzavacca P et al. Effects of clonidine on the cardiovascular, renal and inflammatory responses to experimental bacteremia. Shock. 2019;51(3):348-55.

73. Lankadeva YR et al.

Dexmedetomidine reduces norepinephrine requirements and preserves renal oxygenation and function in ovine septic acute kidney injury. Kidney Int. 2019;96(5):1150-61.

74. Hsing $\mathrm{CH}$ et al. a2-adrenoceptor agonist dexmedetomidine protects septic acute kidney injury through increasing BMP-7 and inhibiting HDAC2 and HDAC5. Am J Physiol Renal Physiol. 2012;303(1):F1443-53.

75. Chen $Y$ et al. Dexmedetomidine protects against lipopolysaccharideinduced early acute kidney injury by inhibiting the iNOS/NO signaling pathway in rats. Nitric Oxide. 2019:85:1-9

76. Koca $\cup$ et al. The effects of dexmedetomidine on secondary acute lung and kidney injuries in the rat model of intra-abdominal sepsis. ScientificWorldJournal. 2013;2013:292687.

77. Feng $X$ et al. Dexmedetomidine ameliorates lipopolysaccharideinduced acute kidney injury in rats by inhibiting inflammation and oxidative stress via the GSK-3B/Nrf2 signaling pathway. J Cell Physiol. 2019;234(10):18994-9009.

78. Tan F et al. Dexmedetomidine protects against acute kidney injury through downregulating inflammatory reactions in endotoxemia rats. Biomed Rep. 2015;3(3):365-70.

79. Kang $\mathrm{K}$ et al. Dexmedetomidine protects against lipopolysaccharideinduced sepsis-associated acute kidney injury via an a7 nAChRdependent pathway. Biomed Pharmacother. 2018;106:210-6.

80. Osawa EA et al. Effect of furosemide on urinary oxygenation in patients with septic shock. Blood Purif. 2019;48(4):336-45.

81. Okazaki $\mathrm{N}$ et al. Beneficial effects of vasopressin compared with norepinephrine on renal perfusion, oxygenation and function in experimental septic acute kidney injury. Crit Care Med. 2020;48(1):e9518.

82. Cioccari $L$ et al. The effect of dexmedetomidine on vasopressor requirements in patients with septic shock: a subgroup analysis of the Sedation Practice in Intensive Care Evaluation [SPICE III] Trial. Crit Care. 2020;24(1):441.

83. Nakashima T et al. Dexmedetomidine improved renal function in patients with severe sepsis: an exploratory analysis of a randomized controlled trial. J Intensive Care. 2020;8:1.

84. Lankadeva Y et al. Renal medullary hypoxia: a new therapeutic target for septic acute kidney injury? Semin Nephrol. 2019;39(6):543-53.

85. Kellum JA et al. Developing a consensus classification system for acute renal failure. Curr Opin Crit Care. 2002;8(6):509-14.

86. Englberger $L$ et al. Clinical accuracy of RIFLE and Acute Kidney Injury Network (AKIN) criteria for acute kidney injury in patients undergoing cardiac surgery. Crit Care. 2011;15:R16. 